\title{
Optimization of InGaN Laser Diodes Based on Numerical Simulations
}

\author{
K. SAKOWski ${ }^{a, b}$, P. Strak ${ }^{a}$, S. KrukOWski ${ }^{a, c}$ AND L. MARCinKOWsKI ${ }^{b}$ \\ ${ }^{a}$ Institute of High Pressure Physics, Polish Academy of Sciences, Sokołowska 29/37, 01-142 Warsaw, Poland \\ ${ }^{b}$ Department of Mathematics, Computer Science and Mechanics, University of Warsaw, S. Banacha 2, 02-097 \\ Warsaw, Poland \\ ${ }^{c}$ Interdisciplinary Centre for Materials Modeling, Warsaw University, A. Pawińskiego 5a, 02-106 Warsaw, Poland
}

\begin{abstract}
Simulations of blue and green laser diodes with InGaN quantum wells are presented. In this study, a particular emphasis on efficiency and optical power of the structures was placed. Effect of the aluminum content in an electron blocking layer on the electron overflow and efficiency is discussed. Substantial decrease of efficiency of laser diodes is reported for low aluminum levels. It is also shown that polarization charges existing in AlInGaN heterostructures grown on GaN polar direction and low ionization degree of magnesium acceptors lead to high resistance of these devices. These effects hinder the carriers from reaching an active region and consequently they impose high operating voltages.
\end{abstract}

DOI: 10.12693/APhysPolA.129.A-33

PACS: 42.55.Px, 02.60.Cb

\section{Introduction}

Green and blue laser diodes based on the gallium nitride are of interest to experimental and theoretical physicists. Growth methods of these devices and principles of their operation are the subjects of studies at the present time. Applications result in requirement of powerful and effective lasers. To make devices more efficient, it is necessary to study still unknown physical mechanisms. The computational power of contemporary computers allows to perform fast numerical simulations [1, 2], which can be used to determine physical phenomena governing operation of such devices.

In our research we focus on problems with operation of such devices from the perspective of the electric properties and the carrier flow. First, we discuss the aluminum doping level in the electron blocking layer (EBL). High aluminum concentration increases a barrier for electrons, reducing the electron overflow and preventing them from escaping the active region. On the other hand, growth conditions of such layers are different than InGaN quantum wells (QW), so introducing high aluminum concentration may lead to degradation of QWs. Our aim is therefore to determine optimal $\mathrm{Al}$ level, where the electron overflow is minimized and the aluminum content is possibly low.

Then, we pass to the problem of magnesium doping in the $p$-type region. Since Mg acceptors have high activation energy, it is natural to improve conduction in the $p$-type region by high $\mathrm{Mg}$ concentration. However, this approach may lead to growth problems or the light absorption [3]. Therefore, we would like to study the benefits of high $\mathrm{Mg}$ concentration, to determine whether it is worth of taking this parameter into account and which doping level to use.

\section{Structure}

Simulations presented in this paper are based on the following example of the laser heterostructure. It starts with one microm $n$-GaN layer, followed by $550 \mathrm{~nm}$ $n$ - $\mathrm{Al}_{8 \%} \mathrm{Ga}_{92} \% \mathrm{~N}$ cladding and $100 \mathrm{~nm} n$-GaN waveguide. Then the active part consists of a $20 \mathrm{~nm} n$ $\mathrm{In}_{1.5 \%} \mathrm{Ga}_{98.5 \% \mathrm{~N}}$ layer, a $4 \mathrm{~nm}$ undoped $\mathrm{In}_{17 \%} \mathrm{Ga}_{83 \%} \mathrm{~N}$ quantum well and a $22 \mathrm{~nm} n-\mathrm{In}_{1 \%} \mathrm{Ga}_{99 \%} \mathrm{~N}$ cap. It is followed by a $20 \mathrm{~nm} p$-AlGaN EBL, a $100 \mathrm{~nm} p$-GaN waveguide, a $400 \mathrm{~nm} p-\mathrm{Al}_{8 \%} \mathrm{Ga}_{92} \% \mathrm{~N}$ cladding and a $30 \mathrm{~nm}$ $p$-GaN contact layer. Information on the details of the model and numerical methods used by us may be found in Refs. $[4,5]$.

\section{Aluminum content in EBL}

Our first problem is to determine the optimal level of aluminum doping in the electron blocking layer. We performed simulations of the laser structure from Sect. 2 with aluminum content in the EBL varying from 0 to $30 \%$. Results are presented in Tables I and II. Increasing aluminum content generally also increases efficiency of the device, but only up to a certain level. For example, under $5 \mathrm{~V}$ bias we reach the maximum of $55 \%$ efficiency for $15 \% \mathrm{Al}$ in the EBL.

The explanation of these phenomena is as follows. Lower $\mathrm{Al}$ content decreases the barrier for electrons, allowing them to escape from the active region to the $p$ type region. Then, they either recombine with abundant holes in the $p$-type region (recombination loss), or they reach the contact. In the latter case the electrons generate energy loss not only at the contact, but also along their way through the $p$-type region, as the potential differences for biases larger than $4 \mathrm{~V}$ are quite significant there (conduction loss). 


\section{TABLE I}

Simulation results of the laser structure (Sect. 2) versus aluminum content in the electron blocking layer for $5 \mathrm{~V}$ bias. I stands for the current. Optical power is estimated by the radiative recombination amount in the QW multiplied by the band gap. Power loss accounts for the radiative recombination outside the $\mathrm{QW}$, non-radiative recombination on the whole device, recombination of overflow carriers on contacts and the resistance.

\begin{tabular}{c|c|c|c|c}
\hline \hline EBL Al & I [A] & $\begin{array}{c}\text { Power } \\
\text { loss [W] }\end{array}$ & $\begin{array}{c}\text { Optic } \\
\text { power [W] }\end{array}$ & Eff. \\
\hline $0 \%$ & 0.364 & 1.713 & 0.108 & $6 \%$ \\
$3 \%$ & 0.528 & 2.471 & 0.167 & $6 \%$ \\
$6 \%$ & 0.373 & 1.551 & 0.313 & $17 \%$ \\
$9 \%$ & 0.235 & 0.740 & 0.435 & $37 \%$ \\
$12 \%$ & 0.169 & 0.411 & 0.435 & $51 \%$ \\
$15 \%$ & 0.155 & 0.349 & 0.424 & $55 \%$ \\
$20 \%$ & 0.147 & 0.328 & 0.408 & $55 \%$ \\
$30 \%$ & 0.134 & 0.298 & 0.369 & $55 \%$
\end{tabular}

TABLE II

Simulation results of the laser structure (Sect. 2) versus aluminum content in the electron blocking layer for $6 \mathrm{~V}$ bias.

\begin{tabular}{c|c|c|c|c}
\hline \hline EBL Al & I [A] & $\begin{array}{c}\text { Power } \\
\text { loss [W] }\end{array}$ & $\begin{array}{c}\text { Optic } \\
\text { power [W] }\end{array}$ & Eff. \\
\hline $0 \%$ & 0.689 & 3.949 & 0.185 & $4 \%$ \\
$3 \%$ & 0.679 & 3.846 & 0.230 & $6 \%$ \\
$6 \%$ & 0.650 & 3.424 & 0.475 & $12 \%$ \\
$9 \%$ & 0.481 & 2.125 & 0.762 & $26 \%$ \\
$12 \%$ & 0.296 & 1.039 & 0.739 & $42 \%$ \\
$15 \%$ & 0.266 & 0.868 & 0.727 & $46 \%$ \\
$20 \%$ & 0.255 & 0.824 & 0.709 & $46 \%$ \\
$30 \%$ & 0.240 & 0.776 & 0.665 & $46 \%$
\end{tabular}

It is also interesting why the conduction loss is much greater than the recombination loss for $5 \mathrm{~V}$ and $6 \mathrm{~V}$ bias. Intuitively we could expect any escaped electron to recombine in $p$-type region due to abundance of holes. However, due to the electric field, the concentration of electrons is several orders of magnitude smaller than the hole concentration and they move rapidly. Even if they recombine, they still travel to the contact losing its energy, forming holes traveling in the opposite way.

For the optical power, we observe a different pattern: it also increases rapidly up to a maximum level, but then it slightly drops with the $\mathrm{Al}$ content. For example, under $5 \mathrm{~V}$ bias, the maximal optical power is reached for $9-12 \%$ $\mathrm{Al}$. This is an additional problem with a high $\mathrm{Al}$ content in EBL, as it also creates a certain barrier for holes. It is disadvantageous, as it prohibits holes from reaching the active region. Note that in general increasing the EBL barrier leads to lower total current.

We have also performed simulations of the laser structure with $8 \%$ In in the cap (Table III), to study a more general setting. Then the barrier on the cap/EBL inter-
TABLE III

Simulation results for the laser structure (Sect. 2) versus aluminum content in the electron blocking layer for $5 \mathrm{~V}$. Indium content in the cap was increased to $8 \%$.

\begin{tabular}{c|c|c|c|c}
\hline \hline EBL Al & I [A] & $\begin{array}{c}\text { Power } \\
\text { loss [W] }\end{array}$ & $\begin{array}{c}\text { Optic } \\
\text { power [W] }\end{array}$ & Eff. \\
\hline $0 \%$ & 0.408 & 1.602 & 0.439 & $22 \%$ \\
$3 \%$ & 0.212 & 0.557 & 0.501 & $47 \%$ \\
$6 \%$ & 0.183 & 0.424 & 0.491 & $54 \%$ \\
$9 \%$ & 0.177 & 0.404 & 0.482 & $54 \%$ \\
$12 \%$ & 0.174 & 0.396 & 0.473 & $54 \%$
\end{tabular}

face is higher for the same aluminum content in the EBL. The general trend is similar as in the previous case, but then the maximal efficiency/optical power is reached for $3-6 \% \mathrm{Al}$ in EBL.

These two examples lead to the conclusion that the aluminum content in EBL should be chosen in accordance to the material in the $n$-type cap preceding the EBL. Higher indium content allows for decrease of $\mathrm{Al}$ content in EBL.

\section{4. $\mathrm{Mg}$ doping of $p$-type region}

In this section we would like to discuss the role of magnesium acceptor doping on operation of laser structures. In simulations we use the structure described in Sect. 2 with variable $\mathrm{Mg}$ concentration in the $p$-waveguide and $p$-cladding. The length of $n$-cap was also shortened to $2 \mathrm{~nm}$ to reduce impact of the recombination loss on the simulation. The indium content in the quantum well is $25 \%$ and the aluminum content in the EBL is $20 \%$.

Results are presented in Table IV.

TABLE IV

Simulation results for the laser structure (Sect. 4) versus magnesium concentration in the $p$-type region $5 \mathrm{~V}$ and $6 \mathrm{~V}$ bias.

\begin{tabular}{c|c|c|c|c|c}
\hline \hline $\begin{array}{c}\text { Mg conc. } \\
{\left[\mathrm{cm}^{-3}\right]}\end{array}$ & I [A] & $\begin{array}{c}\text { Power } \\
\text { loss [W] }\end{array}$ & $\begin{array}{c}\text { Optic } \\
\text { power [W] }\end{array}$ & Eff. & $\begin{array}{c}\text { Resist. } \\
{[\Omega]}\end{array}$ \\
\hline \multicolumn{5}{c}{$U=5[\mathrm{~V}]$} \\
\hline $10^{18}$ & 0.004 & 0.008 & 0.010 & $54 \%$ & 1355 \\
$5 \times 10^{18}$ & 0.046 & 0.105 & 0.125 & $54 \%$ & 109 \\
$10^{19}$ & 0.075 & 0.171 & 0.204 & $54 \%$ & 67 \\
$3 \times 10^{19}$ & 0.137 & 0.313 & 0.374 & $54 \%$ & 36 \\
$5 \times 10^{19}$ & 0.175 & 0.399 & 0.476 & $54 \%$ & 29 \\
\hline \multicolumn{5}{c}{$U=6[\mathrm{~V}]$} \\
\hline $10^{18}$ & 0.016 & 0.052 & 0.043 & $45 \%$ & 376 \\
$5 \times 10^{18}$ & 0.099 & 0.323 & 0.269 & $45 \%$ & 61 \\
$10^{19}$ & 0.155 & 0.509 & 0.423 & $45 \%$ & 39 \\
$3 \times 10^{19}$ & 0.284 & 0.932 & 0.774 & $45 \%$ & 21 \\
$5 \times 10^{19}$ & 0.365 & 1.198 & 0.995 & $45 \%$ & 16
\end{tabular}

We observe that the optical power of the device increases with the $\mathrm{Mg}$ doping. Such a result is expected, as generally it is a consequence of the high activation energy of the magnesium acceptor. However, a more subtle factor is related to polarization charges on interfaces of 
laser structures. Note the resistance in function of the $\mathrm{Mg}$ concentration. We observe the decrease of the resistance of the structure when we increase the $\mathrm{Mg}$ concentration, but the most spectacular difference is between concentrations $10^{18} \mathrm{~cm}^{-3}$ and $5 \times 10^{18} \mathrm{~cm}^{-3}$. High resistance for $10^{18} \mathrm{~cm}^{-3}$ is caused by the polarization charge on the waveguide/cladding interface (see Fig. 1).

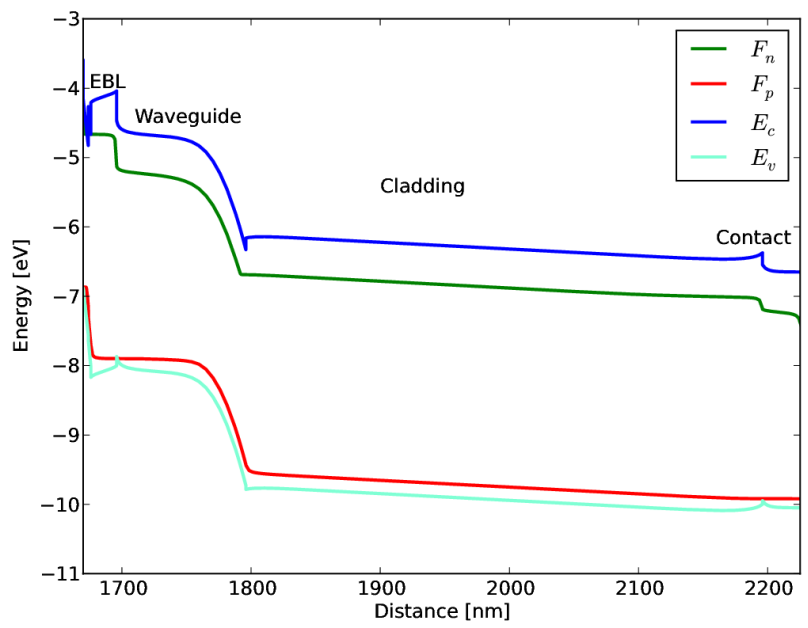

Fig. 1. Band diagram of the $p$-type region of the laser structure for $\mathrm{Mg}$ doping $10^{18} \mathrm{~cm}^{-3}$ and for $6 \mathrm{~V}$ bias.

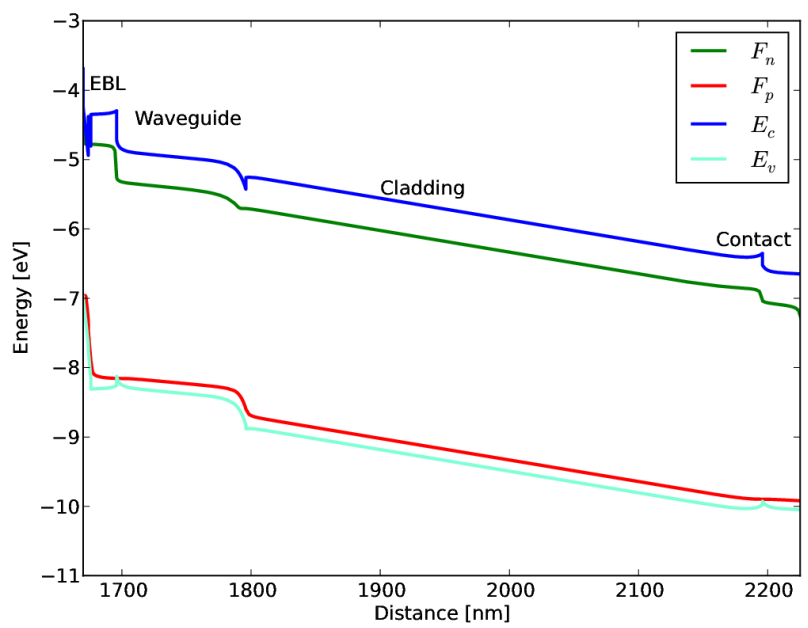

Fig. 2. As Fig. 1 for $\mathrm{Mg}$ doping $10^{19} \mathrm{~cm}^{-3}$.
It pushes out holes away from the interface deep into the waveguide and increases greatly the resistance of the depleted fragment. As a consequence, most of the potential difference is located in the waveguide. If we increase the concentration of holes, this polarization charge will be screened and its impact on the resistance can be significantly reduced (see Fig. 2).

Note that the resistance decrease has no noticeable influence on the efficiency of the device, as it does not increase the carrier overflow.

The conclusion of these results is to use the highest possible magnesium concentration in the $p$-type region. Please note, however, that the numerical model used in this study does not account for increased absorption in such case, which could make the device less efficient in real experiments. Also growth of highly $\mathrm{Mg}$-doped layers, depending on a growth method, may lead to severe problems, like the polarization inversion or acceptor passivation. Therefore, we suggest to make the concentration possibly high, but the actual concentration level should be adjusted experimentally and may vary depending on the growth method.

\section{Acknowledgments}

The research was funded by Polish National Science Center on the basis of the decision DEC2011/03/D/ST3/02071.

\section{References}

[1] P.A. Markowich, C.A. Ringhofer, C. Schmeiser, Semiconductor Equations, Springer-Verlag, Wien 1990.

[2] S. Selberherr, Analysis and Simulation of Semiconductor Devices, Springer-Verlag, Wien 1984.

[3] M. Kuramoto, C. Sasaoka, N. Futagawa, M. Nido, A.A. Yamaguchi, Phys. Status Solidi A 192, 329 (2002).

[4] K. Sakowski, L. Marcinkowski, S. Krukowski, Lecture Notes in Computer Science 8385, 551 (2014).

[5] K. Sakowski, L. Marcinkowski, S. Krukowski, S. Grzanka, E. Litwin-Staszewska, J. Appl. Phys. 111, 123115 (2012). 